\title{
IDENTIFYING THE EVOLUTION OF CITIES' ARCHITECTURAL CHARACTERS IN CONNECTION TO GLOBAL EVENTS OVER TIME
}

\author{
YOMNA YASSER FAHMY, DINA MAMDOUH NASSAR \& ZEYAD TAREK ELSAYAD \\ Architectural Engineering Department, Faculty of Engineering, Alexandria University, Egypt
}

\begin{abstract}
In the past decade, many of the world's aspects were subjected to a great change caused by many events that took place in various countries and yet affected almost the whole world, which is now explained by the term "globalization". That recent picture of the world is a result of many accumulated changes that had happened over a long period of time, which of course had an influence on people's lives. Architecture was deeply influenced by these changes as it represented them in its concepts and designs through consecutive eras as a witness to the different events that took place. However, sometimes the architectural changes were slight, but other times the changes were deeper which indicates how people's lives were affected back then, which eventually affected the architectural characters of many cities across the globe. This research connects the cycles of globalization with the architectural evolution and the changes in local architectural identities over time to detect the severity of the impact of globalization on the architectural products. Therefore, the study focuses on two main points: the impact of globalization forces on architecture, and the evolution of the architectural identity features in three cities with deep rooted history, which are Paris, Moscow and Cairo. The study analyzes architectural products from subsequent years, which were subjected to many world-changing global events in order to track the change and to detect the era in which architecture lost most of its unique identity in these cities. Eventually it was clear that the last phase of architectural development - which extends to the present time - had the most brutal impact on people, due to the openness that led to globalize cultures and standardize norms. Architects focused on the building's functions rather than the local identity, which eventually resulted in making the replicas of buildings around the world without a unique character for each place.

Keywords: architectural identity, architectural character, globalization, globalization forces.
\end{abstract}

\section{INTRODUCTION}

Over the course of history, architecture played an important role in manifesting the identities of cities; as each era had its unique architecture that represents the culture and ideologies of people, as well as their values and traditions. Moreover, architecture isn't only a witness of past risen and fallen civilizations, but also an evidence of their existence for the upcoming generations to analyze and learn from. In fact, any architectural identity of any place was formed over a long period of time by adding each generation's imprint of their evolved thoughts and ideas to the old inherited identity features of their ancestors, leading it to cope with their present culture and beliefs, which allowed architecture to gain its continuity over time.

The world has encountered many challenges through of history that changed many of its norms due to the openness and connections between distant countries that have grown stronger every day more that the day before. That openness and ability to connect countries politically, economically and even culturally was later referred to by the term "globalization" which had touched nearly every aspect of peoples' lives over time and forced other terms to appear in order to explain the changes happening in many fields. For instance, the term "global culture" describes the resemblance in people's ideas and preferences around the 
world which is caused by what is called "globalization forces" which were defined as the main dimensions of globalization. These dimensions are political, economic and cultural.

These changes affected people's lives and were manifested in their lifestyles and their architecture as a result. Therefore, the current features of architecture are a result of many phases of development. In the past, architecture represented the identity of the place it was located in, which allows the viewer to speculate the characteristics of the place through its architectural features. For instance, some design principles are used to match the culture of users, also, the building materials and façade and roof designs represent the climatic and geographical status of the place, which integrates the building in its environment and creates a bond between it and its users. The changes in architectural principles and values caused by globalization forces were sometimes viewed as an opportunity to thrive and other times as a way to obliterate the local character and identity. However, as many cities were subjected to these changes, each city evolved differently according to the level of technological development that reached it, while some cities maintained parts of their identity in the process. The research analyzes architectural identities of three megacities from different geographical locations; which are, Moscow, Paris and Cairo to track the levels of change over the cycles of globalization. As, Moscow and Paris were mostly in the center of global events, their architecture was more influenced and rapidly developing. On the other hand, Cairo as a third world city has encountered delay in technological development. That made its architecture change slowly while maintaining parts of its identity along the way.

\section{ARCHITECTURAL CHARACTERISTICS DEFINING A CITY'S IDENTITY}

A city's identity is produced from the characteristics of its societies, which represent the local culture of its inhabitants as well as the natural features of the city. Each era that passes by adds to the historical background of the city, which eventually contributes in shaping the city's unique identity. The city's built environment with its streets, squares and buildings represent the interaction between people and their surroundings, therefore, any change in the fabric of that built environment indicates a change in people's lives or even causes that change. However, if architecture is considered as a mirror to the social, political and economic status of the society, then analyzing architecture of anytime can help in understanding these circumstances of the time it was established in [1].

Despite that architecture has two main aspects; form and function, however, whenever people view any architectural product, the first thing that catches their attention is its form and visual details, which gains their approval or rejection. Therefore, visual perception is an essential aspect of architectural criticism, as people judge a building's form, materials and colors before getting to experience its function [2]. [2] According to Lynch, the environmental image consists of three main elements which are identity, structure and meaning and they always appear together. Image identity can be recognized if the object has distinctive elements that distinguish it among other objects, the structure represents connections between the objects, and structure must have a sentimental value and emotional meaning to the viewer [3].

\section{THE IMPACT OF GLOBALIZATION ON SOCIETIES}

The term "Globalization" was shaped in the second half of the 20th century. It was defined as the interaction between social relations linking distant societies together; that a local happening might occur as a result to an event in another society located miles away [4]. By time, globalization forces and their dominance over the world participated in creating a common global culture, similar identities and life styles and created a global network between near and distant societies. The rapid technological development kept spreading in 
the entire world making people stray away from their localized ideologies and consider them as old ideas that need changing, which undermined the old devotion of place and society. The transmission of ideas and values around the world extended social relations and created what is called "cultural globalization", which involves the formation of shared cultural identities represented in shared norms, and knowledge, which caused deep interactions between different cultures [5].

As a result to these changes caused by globalization, many societies got wealthy and developed after decades of poverty and ignorance. On the other hand, some societies were copying the cultures of developed ones and their architecture as well, which eventually caused their local identity to get lost in the process and them being left with a replica of a foreign identity they know nothing about but its superficial image. Architecture - as a witness to these events - kept representing these changes in people's culture and lifestyle through time till it reached its current status. However, many third world cities, especially the ones that have experienced rapid growth and development in the past two decades, were deeply affected by the contradicting forces of globalization and localization, therefore, they created a "co-existence" model which embraces the characteristics of modernization without neglecting the traditional features of the society. That model was essential to maintain their identity when globalization forces were affecting every aspect of people's lives which led them to a serious case of "identity loss" [6].

\section{CLASSIFYING THE GLOBALIZATION CYCLES}

The last global era is only a manifestation of the enormous global interaction that has been building up since the beginning of humanity. Each period of globalization had its own distinctive characteristics that surely affected the eras that came after. That's how the latest stage of globalization was formed, by developing global forces over a long period of time [1].

Researchers have divided the history of globalization into cycles, as many waves of change have hit the world over time. However, some researches divided them into five cycles, as the age of exploration in the 15th and 16th centuries wasn't counted as a cycle, but more of a preparation era, which starts it in the 19th century with Globalization 1.0 that ends by 1914, Globalization 2.0 begins in 1945 and lasts till 1989, Globalization 3.0 begins in 1989 and ends in 2008, and lastly Globalization 4.0 starts in 2008 and is still ongoing [7].

Thomas L. Friedman divided globalization history into three periods; Globalization 1.0 (1492-1800) which brought countries closer to each other by the trade routes, Globalization 2.0 (1800-2000) in which companies where affected the most, collaborations and trade between them were facilitated, and Globalization 3.0 (2000-present) which affected people's culture and lifestyle. As the world operates with people and for people, that last cycle had the most influences on the overall changes taking place around them [8].

Architecture was indeed affected by the globalization forces, as its features were changed as a response to the historical events, and to the social, economic, and technological developments. Therefore, the architectural cycles of change parallel to those of globalization, as they would represent the architectural analogy of the world's development. That architectural development would be divided into five cycles marking the main turning points in the history of architecture which helped in forming what is now called "contemporary architecture". The industrial revolution was one of the main turning points in the history of architecture, therefore, it marks the first substantial change in the architectural product. The time between 1918 and 1945 witnessed the two world wars which caused lots of destruction to the world followed by the need to rebuild and reconstruct. Also, the oil discovery in the Arabian Gulf area affected the entire world and had a great impact on architecture. And lastly 
the new technological developments of the 21st century contributed in introducing new design tools to architects which appeared in their designs.

To sum it up, the global architectural development cycles would be: (I) pre-industrial revolution (before 1840); (II) Post industrial revolution (1840-1914); (III) post world wars (1945-1970); (IV) post oil discovery in Arabian Gulf (1960-2000); and (V) from 2000 to present.

\section{THE GLOBAL-ARCHITECTURAL CYCLES OF CHANGE}

As architecture is deeply connected to the human life and is constantly representing the developing needs of the society, it has been essential for it to react to the ongoing changes in the world that are caused by the globalization forces. Many architectural similarities can be noticed between cities from east to west, in their old and new architecture. These similarities were caused by the trending architectural styles of each time that have been embraced by many architects in different spots of the world. By the early 20th century, architects started to develop their design techniques in order to cope with the developing technologies, industries, as well as social and political statuses, Therefore, the "international style" was born. However, about a century later, architecture was pressured to globalize, as architects were interested in studying other architects' works in various places in the world. The technological development allowed them to analyze their work in high quality pictures in magazines and journals, which gave them the opportunity to scan the world's architecture and share design concepts and try to imitate them with their different materials, such as, glass, aluminum, titanium. Whenever these materials weren't available in the place of construction, they were imported in order to complete the whole picture of the façade. Which explains how the globalization forces facilitated the appearance of glassy-metal facades in many cities around the world [9].

Many modern architects and planners in the past decades have neglected the human needs in the process of designing cities. They focused on making unique individual buildings rather than creating a complete balanced built environment with well-designed urban spaces. However, since the millennium, many people migrated from rural areas to the cities, which caused cities to grow bigger in size and will continue that growth for the upcoming years as well. In the 1900 s only $10 \%$ of the world population lived in cities, while by the year 2007 that percentage increased to reach about $50 \%$ and experts expect it to keep increasing till it reaches $75 \%$ by the year 2050 . That growth calls for these cities to make serious decisions regarding their planning options in order to focus on people's needs [10].

The global adoption of a universal style of architecture may have caused the architectural identities of many cities to be blurred or neglected in favor of creating remarkable buildings. However, the changes seen in building facades in present time are the product of a long time interaction with many globalization forces in many aspects of people's lives, which eventually reflected on their architecture. That change should have had a connection to the cultural background of people in different distant megacities such as, Moscow, Paris and Cairo. But, on the contrary, many similarities where spotted in the architectural products despite of the clear differences in culture and history of these Counties.

\subsection{1st cycle: Pre-industrial revolution}

When the Europeans discovered the Americas and Australia in the 15th century, knowledge was expanded across the globe, which is the initial simplified concept of globalization. That discovery had a great impact on the world's economic and political statuses, as these lands were dominated by the colonizers' culture and architecture and cross oceanic trade routes 
were created, which helped in transferring architectural trends and ideas from west to east [1]. Europe witnessed the rise of many architectural styles as a response to the changes in the economic, political and cultural aspects of that time. These styles eventually spread to various countries years after their emergence in their home countries. The early Romanesque, was followed by gothic, renaissance, baroque and rococo architecture between the years 1000 and 1800. Classicism in architecture emerged between the years 1750 and 1800 as well. These styles were presented by their clear features and concepts in the European architecture of that time, and they have also travelled to other foreign cultures dominated by European colonizers. Eventually many trends faded away and other movements rose to revive them. By that time Russia was reconstructing many of its buildings after the fire of 1812 that destroyed most of the wooden buildings of Moscow. Many of the Russian buildings were designed with the eclectic style, and some used the neo-classicism [11]. In the three chosen megacities, neo-classicism was used in the Bolshoi Theatre in Moscow (Fig. 1) and in Saint Vincent de Paul church in Paris (Fig. 2), where the resemblance in the façade appears in the colonnade and ornamentation. While Egypt at that time was under the dominance of the Ottoman Empire which influenced its architecture and focused on constructing mosques with multiples domes and vaults as well as schools, such as, Mohamed Ali's grand mosque [12] (Fig. 3).

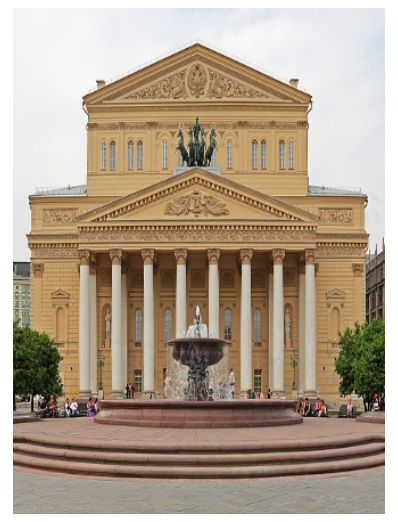

Figure 1: The Bolshoi

Theatre 1825

(Moscow, Russia) [17] [17].

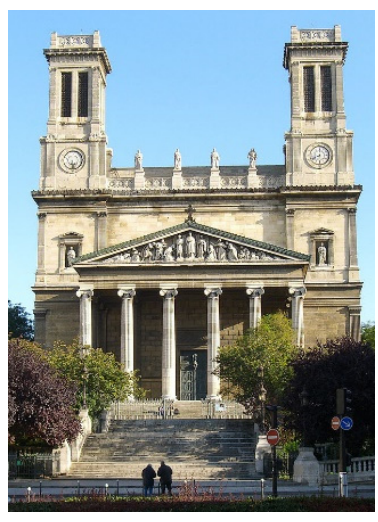

Figure 2: Saint Vincent de Paul 1824 (Paris, France) [17][17].

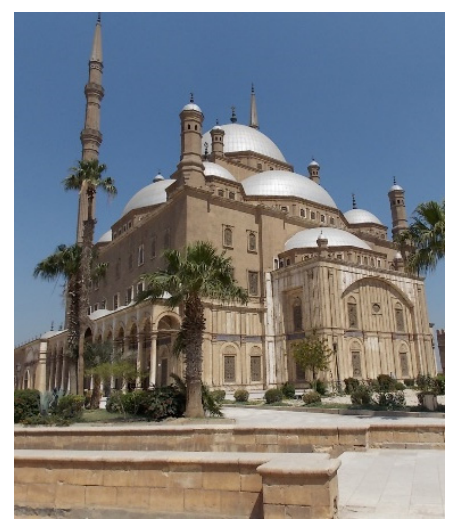

Figure 3: Mohamed Ali Mosque 1830 (Cairo, Egypt) [17][17].

\subsection{2nd cycle: 1840-1914 (post-industrial revolution)}

New manufacturing processes and techniques were introduced to the world after the industrial revolution, which led to using more machines than manpower in the manufacturing process, as well as using new materials like iron and chemicals and harnessing the power of water and steam in the production sector [13]. As a result to the development of new technologies, Architects starting using new materials such as iron and cement in architectural designs as structural materials and decorative elements as well.

In Paris, the Grand Palais (Fig. 4) was constructed using both steel framing structures and reinforced concrete with a glass vault providing natural lighting inside the building. However, in order to maintain the architectural identity of the building, the façade was designed following the beaux-arts style using stone and marble and decorating with French 
ornamentations. On the other hand, Moscow at that time wasn't influenced by the changes in the world until the collapse of the Soviet Union, so the architectural identity was bold in buildings. For example, the state historical museum in Moscow (Fig. 5) was designed based on a Russian version of the baroque style where it represented the identity with its red brick façade, towers, and arched small windows.

By that time, Egypt's architecture was changed by the British colonizers. However, Cairo as a cosmopolitan city has managed to keep some features of its identity despite of the change forced on its architecture. In 1869, the Egyptian khedive ordered to build Omar ElKhayam Palace (Fig. 6) to host guests during the opening of Suez Canal. The Palace was constructed using steel frames and reinforced concrete with interior artifacts imported from Paris and Germany. However, the Islamic identity appeared in the façade where ornamentation with Islamic patterns and arches where used (Fig. 7).

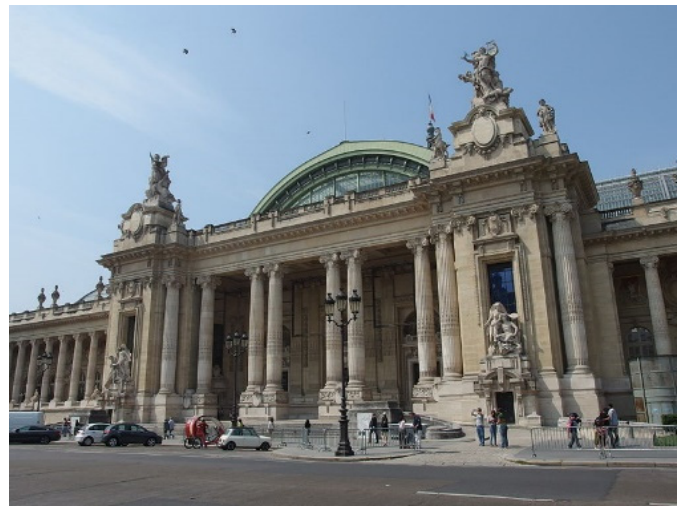

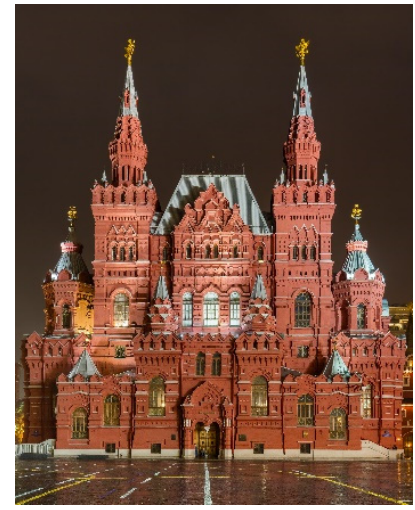

Figure 4: Grand Palais, Paris 1897-1900 [17]. Figure 5: State historical Museum 1872 [17].

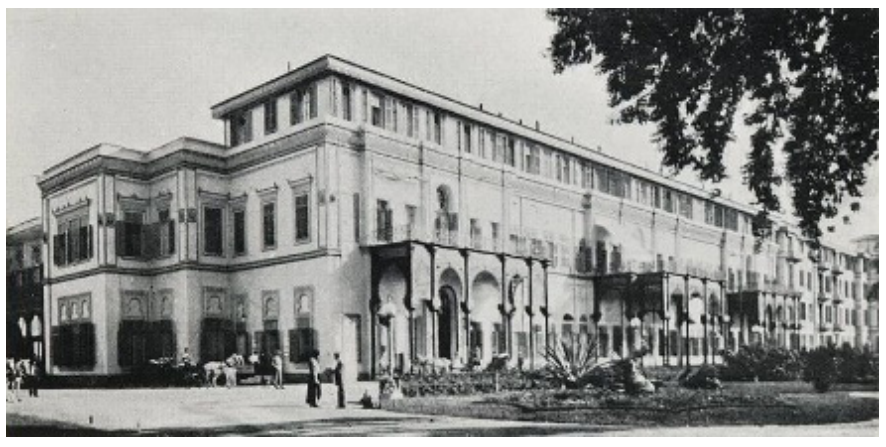

Figure 6: Omar ElKhayam Palace, Cairo 1869 [15].

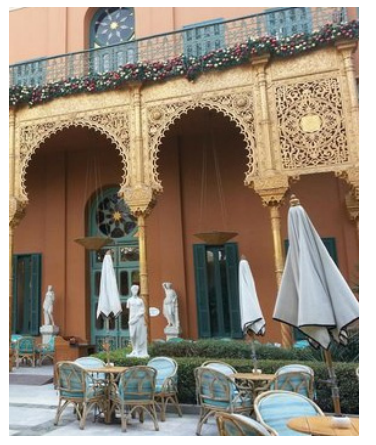

Figure 7: A detail in Omar ElKhayam palace showing the Islamic patterns and arches [16]. 


\subsection{3rd cycle: After the World Wars (1945-1970)}

The main highlight of this cycle was the vast spreading of technology and the huge development it has achieved that facilitated the transaction of knowledge, ideas and communication between people in different continents. This cycle witnessed the birth of the term "modern architecture". However, modernism spreading in the west was a result to the need of reconstructing the damaged cities after World War II. Later on, the trade routes facilitated by globalization forces made it easier for these concepts to travel fast across the globe, and for western architects to put their imprint in eastern societies with these new modern concepts [1].

The UNESCO Heritage Center in Paris (Fig. 8) built in 1958 is an example of how globalization affected architecture, as it's a combined product of three architects with different nationalities; French, Hungarian and Italian, who represented modern architecture in the building's unusual tripod form and the plain facades with rectangular openings. Modernity was also present in Moscow's architecture by that time, as the collapsing of the Soviet Union connected Russia with the rest of the world and allowed new ideologies into people's lives. The Russian White House (Fig. 9) was designed in 1965 with modern principles represented in the monochromatic facades that lack any kind of ornamentation with glass windows repetition.

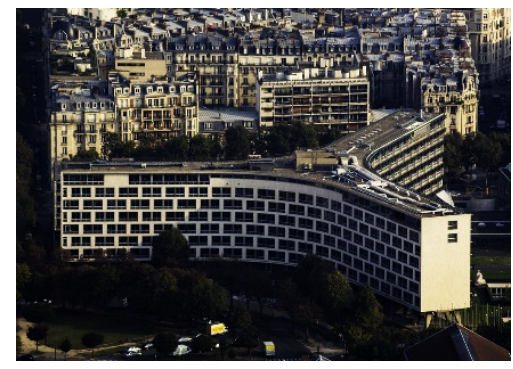

Figure 8: Headquarters of the UNESCO, Paris 1958 [17].

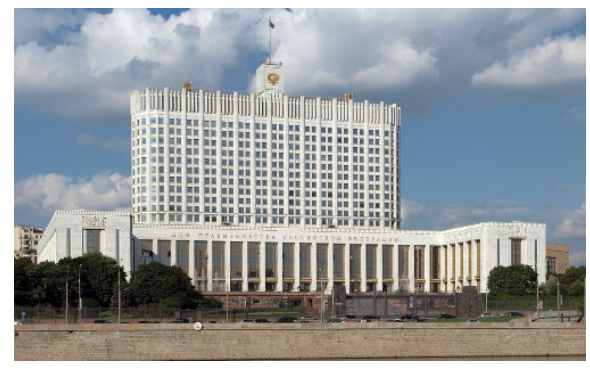

Figure 9: Russian White House, Moscow 1965 [17].

Egyptian modern architecture of that time was a bit close to those of Paris and Moscow. In 1951, King Farouk ordered the demolition of the British army houses in Tahir square and to build a building complex in its location to serve the citizens known as "AlTahrir Complex building" (Fig. 10). The building's design focused on the function over its aesthetics as its facades are plain with now ornamentations or decorations, instead, its facades are busy with an array of rectangular openings. However, its master plan was created in a shape of an arc facing the Tahrir square to match the building's shape with the surrounding urban design.

\subsection{4th Cycle: 1960-2000 (after oil discovery in Arabian Gulf)}

Many Arab countries have encountered some changes in the political, economic and cultural fields by the second half of the 20th century because of many reasons, such as, political independence, population growth, and most importantly; the oil discovery in the Arabian Gulf area which affected the entire world's economy. The rapid financial growth after the oil production caused a major resuscitation in the building industry, as many Arabian Gulf cities were designed from scratch and went under construction shortly after this sudden wealth [6]. 
As technology developed, high tech building style emerged in the late 1960s using lightweight materials and sheer surfaces with application of new technologies in the building. The building of Russian Academy of Science in Moscow (Fig. 11) was one of the unique buildings at the time because of its postmodern design and its twenty two story towers. Modern technology was embedded in the building's design as it is operated by modern systems. People gave it the name "golden brains" because of the golden decoration on the roof that refracts and reflects light in cloudy days.

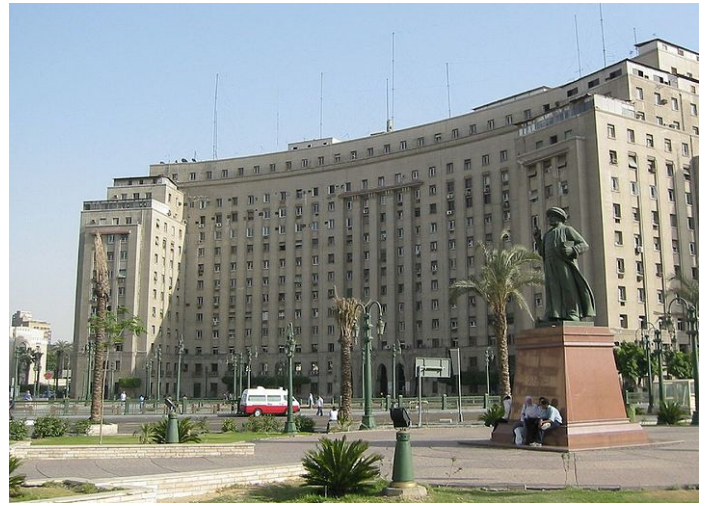

Figure 10: AlTahrir complex building, Cairo 1951 [17].

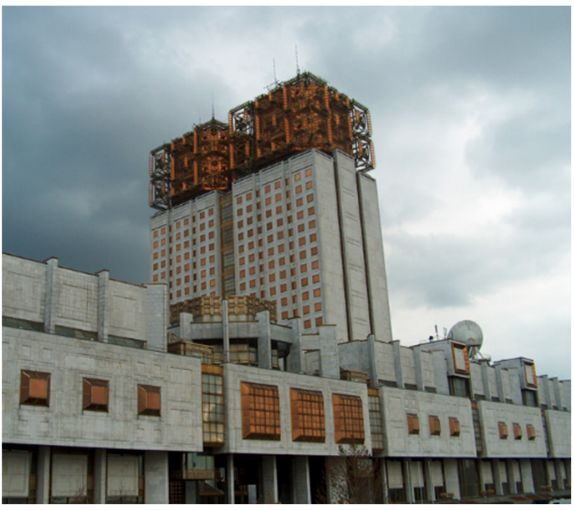

Figure 11: Russian Academy of Science, Moscow 19731990 [17].

In Paris, the Opera Bastille building (Fig. 12) was built in 1989 with modern sound and light technologies to host a huge amount of users. Modern building technologies helped in making a remarkable building using reinforced concrete, glass, aluminum and marble. The building occupies a huge space with its curved form and transparent glass façades and no ornamentations were used to decorate it.

By that time, Egypt was still in the modern architecture era, as it fell behind in receiving modern technologies due to the difficulties of being third world country. The "Al Ahram" Building (Fig. 13) was constructed in 1986 as a headquarters to Al Ahram institution. The building follows modern architecture principles in building and façade design and materials, as it was constructed with reinforced concrete with some horizontal concrete shaders and rectangular openings with a large glass entrance for the building.

\section{5 th cycle: 2000 -present (the 21 st century)}

By the beginning of the 21st century, people started to stray further from their local roots, which they considered "outdated" and started to copy western concepts and ideas as they became the standard for modernity, which was in return represented in their built environment and specifically in their architectural products as their desire to have more modern buildings increased as well [9].

Architecture of that cycle was driven by the countries' need to compete with each other to build the most iconic and tall building, which eventually caused local identity to get lost in the process making the cities look alike [14]. 


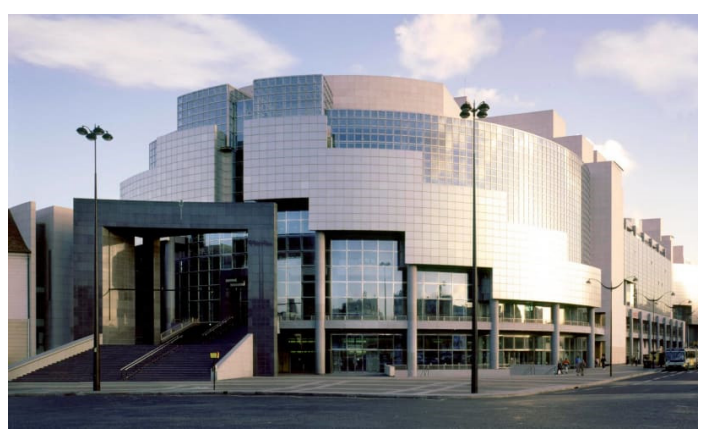

Figure 12: The Opéra Bastille 1989 [19].

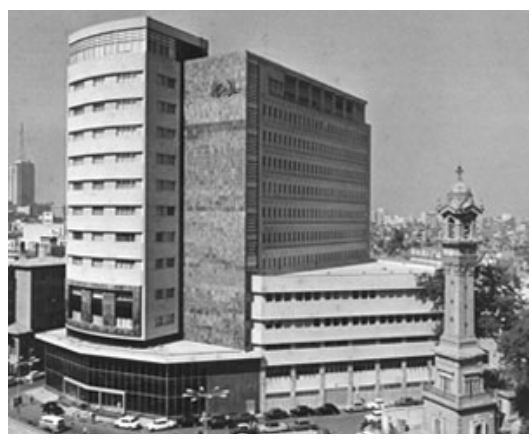

Figure 13: The Al Ahram Building 1968 [20].

In 2005 the CBX Tower (Fig. 14), a $142 \mathrm{~m}$ tall tower was built in Paris as an iconic building with a façade covered entirely with glass with absolutely no sign of any French traditional architectural identity feature. Another example of iconic buildings is the Oko Tower in Moscow (Fig. 15) which were marked as one of the tallest buildings in the world in 2015. The tower is a residential building that includes a hotel. Its façade is made of glass from bottom to roof without pointing to the Russian identity in any way.

On the other hand, Egypt was trying to catch the race of high rise buildings but in a slower pace. In 2003, Nile City Towers (Fig. 16) were constructed on the bank of the Nile as high rise 34 story building with $142 \mathrm{~m}$ tall. Despite the height of the building that resembles the height of the CBX Tower in Paris, it didn't follow the international trend of covering towers' facades with glass. Instead, marble and paint were used beside in the façade to balance the ratio between solids and voids. The local identity was represented in the colonnade at the top of the façade and the little golden domes on top of the towers that connects the building to its ottoman Islamic architecture roots.

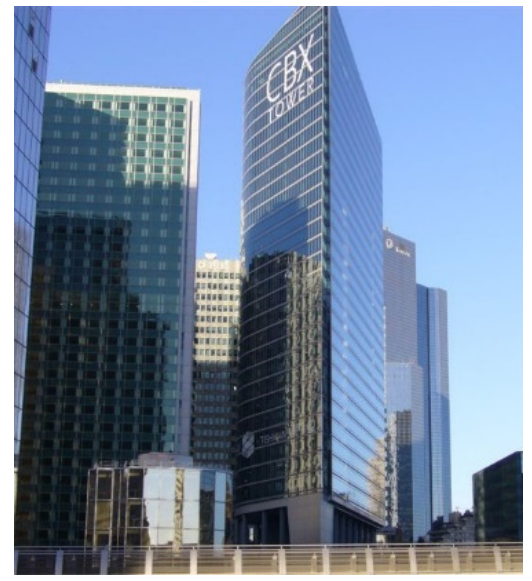

Figure 14: CBX Tower, $2005142 \mathrm{~m}$ tall [17].

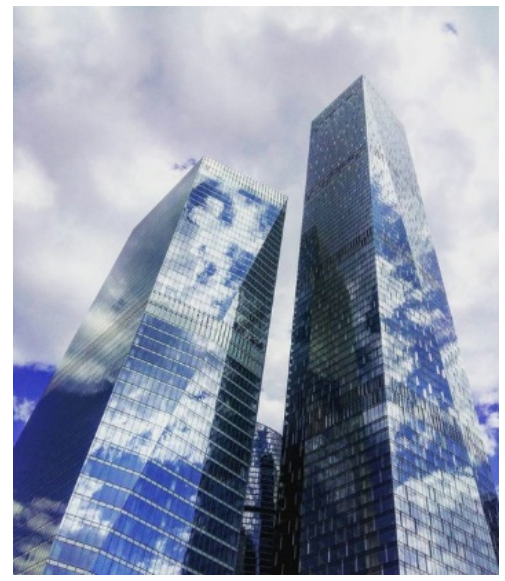

Figure 15: Oko Towers, Moscow [17]. 


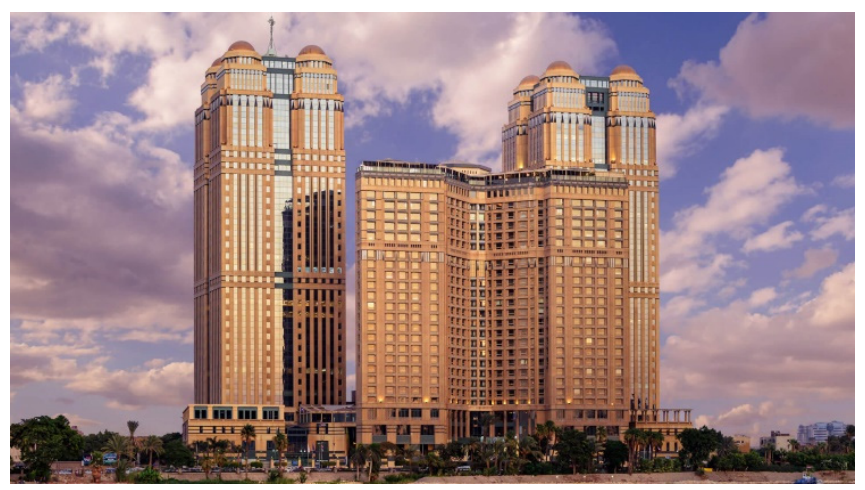

Figure 16: Nile City Towers, Egypt [18].

\section{CONCLUSION}

The research demonstrated that the identities of cities are formed not only by its distinctive climatic and geographical features, but by its people's culture as well. Architecture has always manifested the culture people interacting with it, and that's what created the differences in architectural identities between cities around the world. However, the architectural changes through the course of history can be positively seen as an opportunity for development as long as it responds to people's needs of that time.

Globalization cycles were classified by researches according to the major events that took place in the world causing a great impact on the entire world. However, the research classified them in accordance to the events that had the biggest impact on architecture and changed its features and principles in the world. That classification divided globalization cycles into five cycles; before the industrial revolution, after the industrial revolution, after the world wars, after the oil discovery in the Arabian Gulf, and the architecture of the 21st century. The research demonstrated the architecture of each cycle as the world kept changing over time, ideas were shared easily and new architectural concepts easily travelled around the world. However, as the architectural phases of change went by, some architectural styles were forced on societies regardless of their local identities and traditions.

The research analyzed architectural products from 3 megacities from different geographical locations; which are Paris, Moscow and Cairo. Paris and Moscow held on to their local identities until the 3rd cycle of architectural globalization, but the need to reconstruct cities after the damage caused by world wars was an opportunity for architects to represent new styles in buildings. Therefore, the local identities of both cities was gradually lost and faded from their architectural products until eventually the last cycle had the most brutal impact on their architecture. As countries competed in producing the most iconic buildings, their architectural products became more alike in the last cycle of architectural globalization. Therefore, the CBX tower in Paris and Oko Tower in Moscow share lots of architectural design concepts and show no sign of any identity feature.

On the other hand, Egypt's status as a third world country was actually a blessing. The world's developed technologies arrived to Egypt many years after their emergence in their home countries, which allowed Cairo's architecture to develop slowly and maintain parts of its local identity. Modern architectural concepts dominated building designs in Cairo while trying to put ornamentation and motifs to create a sense of belonging to the building. However, Cairo wasn't completely behind the world in architectural development, in fact, 
many high-rise buildings were constructed within the last cycle of globalization, but with a glimpse of its identity attached to it. That's what kept happening in Cairo for decades. As a cosmopolitan city, it manages to keep its identity against the waves of change while benefiting from the change and coping with the international development.

\section{REFERENCES}

[1] Adam, R., The Globalisation of Modern Architecture: The Impact of Politics, Economics and Social Change on Architecture and Urban Design since 1990, Cambridge Scholars Publishing, 2012.

[2] Elessawy, S., Abulnour, A. \& Wissa, W.M., Quantifying the city's identity: A morphological analysis of the historic Rue Rosette. International Journal of Engineering Research \& Technology (IJERT), 7(3), pp. 136-147, 2018.

[3] Lynch, K.A., The Image of the City, MIT Press, 1960.

[4] Oncu, P.W.A., Space, Culture, and Power: New Identities in Globalizing Cities, Zed Books: London, 1997.

[5] James, P., Globalism, Nationalism, Tribalism: Bringing Theory Back In, Pine Forge Press, 2006.

[6] Mahgoub, Y., Architecture and the Expression of Cultural Identity in Kuwait, 2007.

[7] Osterhammel, J. \& Petersson, N., Globalization: A Short History, Princeton University Press: New Jersey, 2009.

[8] Friedman, T.L., It's a flat world, after all. New York Times Magazine, 2005.

[9] Eldemery, I.M., Globalization challenges in architecture. Journal of Architectural and Planning Research, 26(4), pp. 343-354, 2009.

[10] Gehl, J., Cities for People, Island Press: Washington, 2013.

[11] Strelka Magazine, Moscow's age of wooden architecture, 5 Apr. 2016. www.archdaily.com/784618/a-la-izba-and-faux-stone-moscows-age-of-woodenarchitecture. Accessed on: 12 Sep. 2020.

[12] Lane, E.W., Description of Egypt, American University in Cairo Press, 2000.

[13] Laudes, D.S., The Unbound Prometheus: Technical Change and Industrial Development in Western Europe from 1750 to Present, Cambridge University Press, 1969.

[14] King, A., Spaces of Global Cultures: Architecture Urbanism Identity, Routledge: London, 2004.

[15] Guerville, A.B.D., In New Egypt, E.P. Dutton and Company: New York, p. 31, 1996.

[16] TripAdvisor, Marriott Hotel. www.tripadvisor.com.eg/LocationPhotoDirectLinkg294201-d299719-i93757639-Cairo_Marriott_Hotel_Omar_Khayyam_CasinoCairo_Cairo_Governorate.html. Accessed on: 13 Sep. 2020.

[17] www.wikimedia.org.

[18] www.nilecitytowers.com.

[19] Opera Nationale de Paris. www.operadeparis.fr/en.

[20] Elshahed, M., Cairo Since 1900: An Architectural Guide, The American University Press: Cairo, 2020. 